\title{
A Study on the Countermeasures of Developing "Silk Road" Sports Tourism Resources in Yunnan
}

\author{
Peipei Yang \\ Oxbridge College, Kunming University of Science and Technology, China
}

Keywords: Yunnan; Silk Road; Sports Tourism Resources.

\begin{abstract}
Through documentary methods, it is concluded that the routes of southern silk road are mainly composed of three main lines: the route to Burma and India; the water and land route to Vietnam; the Tea Horse Trade Route linking Nepal and India. The analysis on the present situation of "Silk Road" sport tourism shows some problems such as the lack of fund support, the lack of core competence of the products, the ignorance of sustainable development and the lack of specialized talents, etc. The paper provides countermeasures for the problems.
\end{abstract}

\section{The Concept of "Silk Road" and the Boundary Definition}

The "Silk Road" refers to the general name of the overland business road that crosses Asia and connects Africa and Europe. It is a historic road of business and cultural exchange through more than two thousand years of vicissitudes. "Silk Road" was a main carrier of silk trade at the beginning. Although there are many records in historical documents, there is not a special term. According to historical records, in the territory of China, according to the different historical periods and different geographical boundaries, the "Silk Road" is divided into the grassland "Silk Road", the southern "Silk Road", the maritime "Silk Road" and the overland "Silk Road" [1].

Amount of articles written by related scholars have discussed the overland southern Silk Road in southwest. There are three consensual lines based on the investigation and study within Chinese territory. Sort out as follows:

The Route to Burma and India. The West Line Lingguan Road (The Yak Road). Its direction is as follows: It starts from western Chengdu to Qionglai and heads down south to Mingshan- Ya'anXingjing- Hanyuan- Ganluo- Yuexi- Xide- Mianning- Xichang- Dechang - Miyi- Huili- PanzhihuaYongren in Yunnan- Dayao- Dali

The East Line Wuchi Road. Its direction is as follows: It starts from Chengdu and heads down south along Minjing River to Leshan- Qianwei- Yibin- Wuchi Road- Daguan in Yunnan- Weining in Guizhou- Zhaotong in Yunnan- Qujing- Kunming- Chuxiong- Dali

The West Line and The East Line meet in Dali and extend west to Baoshan- TengchongMyitkyina in Burma(or head south from Baoshan to Ruili and reach Bhamo in Burma ), then go west to Assam of northeast India and reach The Gangetic Plain, passing through Pakistan, Afghanistan, Central Asia and Western Asia. This is known as the "Sichuan-India Road" in history.

The Water and Land Route to Vietnam. The East Line Jinsang Road. Its direction is as follows: It starts form Sichuan to central Yunnan, goes by Nanpan River through Mile, and then gets out of the southeast Yunnan through Wenshan Mountain, and finally reaches Hanoi through Ha Giang and Tuyen Quang along with Panlong River.

The West Line Butou Road. Its direction is as follows: It starts from Sichuan to Dali and extends to Hanoi along with Red River. The Road merges into the sea from Hanoi. It is the most ancient water channel linking Yunnan and IndoChina Peninsula.

The Tea Horse Trade Route Linking Nepal and India. Sichuan-Tibet Line. Its direction is as follows: Chengdu-Ya'an- Kangding- Tibet- Changdu- Nepal- India 
Yunnan- Tibet Line. Its direction is as follows: Pu'er- Dali- Lijiang- Shangri-la- BangdaChangdu- Nepal- India It is basically the same as the Sichuan-Yunnan Railway and the Yunnan-Tibet Highway within Chinese territory nowadays.

The Tea Horse Trade Road is an important route linking Sichuan, Southern Asia and Central Asia in southwest Tibetan areas. It is a business channel dealing with internal China and southern Asia India. Therefore, the Tibetan Area has played an important role in the business communication between southwest China and southern Asia since Tang Dynasty and Song Dynasty. [2]

From the analysis above, it is easy to find that Yunnan is key to connect mainland and overseas.

\section{The Present Situation of the Development of "Silk Road" Sports Tourism Resources in Yunnan}

Yunnan "Silk Road" sports tourism started late, but made rapid progress.In recent years, relying on the geographical and cultural advantages of "Silk Road", Yunnan has successfully held the Kunming international marathon, the Dali international marathon and other events. What's more, the areas along the "Silk Road" held many theme festivals combining the local geographical and cultural advantages which had a good effect.

The Sports Tourism Based on the Nature Resource of "Silk Road" in Yunnan. Yunnan, a major hub of the southern Silk Road, is also an important demonstration zone for the country's "One Belt And One Road" tourism cooperation. In the "Silk Road Tourism Year", The Tourism Development Committee of Yunnan province focused on tourism products and regional cooperation, vigorously promoted and developed Yunnan tourism. It achieved good effects in the tourism industry and tourism market. Several tour lines have been developed combing with the Silk Road.

Two leisure tour lines: the tour of dreaming back to Nanzhao and the tour of visiting the hometown of Nie'er.

Two ecological tour lines: the tour of Baoshan flower sea and the tour of the tea culture in Bingdao of Nanmei in lincang.

Two sightseeing tour lines: the free tour of the border of Wenshan Mountain, the tour of the southern Silk Road in Zhaoshui.

Two Photo-shooting tour lines: the tour of bird photography in Baihua Mountain of Baoshan, the tour of Red River Valley photography of Ailao Mountain.

Two health tour lines: the tour of refreshment and health in Pu'er, and the healthy tour of sanqi in Wenshan.

The Sports Tourism Based on the Culture Resource of "Silk Road" in Yunnan. There are various ethnic groups and culture relics along the tourism line of "Silk Road" in Yunnan. It builds an important status for tourists from domestics and abroad. Yunnan has developed the tourist routes of humanities, folk customs and the Tea Horse Trade Road according to its advantages.

Two culture tour lines: the tour of Southern "Silk Road" in Baoshan, the tour of rainforest in Xishuangbanna.

Two folk custom tour lines: the ecological tour of Green Triangle in Pu'er, the tour of Wa folk customs in Cangyuan.

Two Tea Horse Trade tour lines: the tour of tea culture on the border of Xishuangbanna, the tour of Tea Horse Trade in Lincang.

The Sports Tourism Based on the Relic Resource of "Silk Road" in Yunnan. The "Silk Road" in yunnan has survived the changes of the times and history, leaving many precious historical relics. The Buddhist culture is the main carrier of south Silk Road culture. Throughout the long history, the southwestern region has spread all the Buddhist branches and types, such as Mahayana Buddhism and the Hinayana Buddhism. They were once the ethnic religion of the region. Such as Hinayana Buddhism spread in Dai, Bulang, Benglong, Wa, Achang and so on. Some also permeated the primitive religious culture of the local minority, such as the integration of Avalokitesvara Assembly of Bai nationality and Mahayana Buddhism. In these areas, there are many scenic spots with splendid Buddhist culture. Such as Jizu Mountain(The ashram temple of the Zen patriarch Mahakassapa), Lingjiu Mountain(a famous Buddhist mountain, also known as Diancang Mountain), The three 
pagodas in Dali which has a unique style and great reputation, and the famous Qiongzhu Temple in Kunming. Numerous Buddhist cultural relics along the Silk Road are the distinctive features in Yunnan "Silk Road" cultural tourism circle.

The Sports Tourism Based on the Minority Festival Resource of "Silk Road" in Yunnan. Yunnan, as a minority area, has 26 ethnic groups living together. These minority groups contributed a multi-ethnic culture. Traditional Festivals is the typical example of the culture. The abundant festivals make Yunnan a unique place among the world. Such as the bullfight and wrestling in Shilin, the Torch Festival of Yi nationality, the Double Third singing festival and the third lunar month Street of Bai nationality, the water-splashing festival of Dai nationality, the Wood Drum Pulling festival of Wa nationality, the Munao Singing festival of Jingpo nationality, the Huashan festival of Miao nationality, etc.

\section{The Problems in Developing "Silk Road" Sports Tourism in Yunnan}

Yunnan has various advantages in developing "Silk Road" sports tourism and has made some achievements recently. However, with the enlargement of the sports tourism demand and the development of the "Silk Road" sports tourism in Yunnan, Some problems emerged in the "Silk Road" sports tourism development gradually.

The Lack of Fund Support. The development of the "Silk Road" sports tourism in Yunnan was carried out with the implementation of the national "One Belt And One Road" and Yunnan "Bridgehead" strategy. Because Yunnan is in the southwest, the economy is relatively weak, and the government is underinvested in tourism infrastructure and tourism supporting services. They focused on the development of natural scenery and folk customs in the places like Dali, Lijiang, Shangri-la, Xishuangbanna but ignored the development of sports tourism so that they don't have enough fund to develop large projects of sports tourism. What's more, sports tourism industry itself is an industry with big investment but slow recovery. At the same time, many people's understanding about the sports tourism industry is not comprehensive, the understanding of the continuative development is insufficient. As a result, the "Silk Road" sports tourism investment in Yunnan has few sources and the investment channel is narrow. The shortage of fund also brings a series of problems, such as the lack of promotion and the single issue of sports tourism products.

The Lack of Core Competence. Yunnan province has unique natural scenery, suitable climate, rich ethnic customs and so on. These superior conditions also gives birth to the rich resources of sports tourism. The sports tourism resources are of particular features, and some are even extremely unique in China. There is a helpful idea: "Mine are good while others have, Mine are excellent while theirs are good." But instead of turning these advantages into it, the type of the products is quite single. Accompanied by the upsurge of marathon, Yunnan also has successively held in Kunming marathon and Dali marathon. However, due to the lack of promotion and famous athletes, the events were underwhelming. In addition to these problems, the types of sports tourism projects are not abundant. For example, in some places, with rich geothermal hot springs source like Eryuan, Tengchong, etc, the development of sports tourism projects basically focuses on swimming, water entertainment and hot spring bathing. The redundant construction and single tourism products make the "Silk Road" sports tourism a industry without its own scale and characteristics. In conclusion, the sports tourism products lack the core competitiveness.

The Lack of Cultural Connotation. Yunnan, as the bridge connecting the mainland, south Asia and southeast Asia in the southern Silk Road. Merchants from different countries did business on this road since its opening, they not only enriched the material life but also communicated and fused the culture here. There are many cultures along "Silk Road", including the Buddhist culture and the Caravan culture. In this case, some interesting places were developed, such as Menghuan Pagoda, the Three Pagodas of Chongsheng Temple, Jizu Mountain, the Shuhe ancient town of Lijiang, Shungu ancient town, etc. Although the development of these tourism resources is successful, it also ignores the development of its connotation of sports culture. At present, the development of "Silk Road" sports tourism in Yunnan is still focused on carrying out all kinds of sports competitions and outdoor survival trainings by using its natural resources. Such as hiking, rafting, cross-country activities, etc. 
The Lack of Sustainable Development Consciousness. Tourism development and environmental protection can produce positive interaction, because the good ecological environment is the material basis for the sustainable development of tourism, and the healthy development of the tourism industry not only motivates economic development but also improves the level of people's material and cultural life. At the same time, it promotes the development of environmental protection. [3]

There are some shortcomings in the development of "Silk Road" sports tourism in Yunnan. Some scenic spots put emphasis on economic benefits regardless of the environment protection. Excessive tourists is beyond the reception capacity of environment. It is a great damage to both the resources and tourist experience. Yunnan has so far failed to produce a general plan for the development of the "Silk Road" sports tourism resources. Speaking of developing "Silk Road" sports tourism resources, the aimless development, the lack of scientific thoughts and foresight are seen as a damage to the sustainability.

The Lack of Specialized Talents. The "Silk Road" sports tourism in Yunnan lacks specialized talents, both in the aspect of tour guiding and management. This caused a lot of drawbacks. For example, the behaviors is not professional in the development of sports tourism and the service quality is not high. Sports tourism, especially sports adventure travel, is very special in comparison with other forms of tourism. In routes of this kind of tourism, the natural environment is relatively complex, the change in climate is capricious, the geographical environment can be very bad. It requires the participants to master certain skills. Thus the requirement for the tour guide is high. In addition, compared with the traditional tourism, sports tourism need suppliers have a higher market seizing ability and integration ability for various kinds of sports tourism resources. It also requires a lot of specialized management talents. There are 69 universities in Yunnan. However, only 4 universities are with tourism major and no sports tourism major in all of them. There is a large gap in the specialized talents of sports tourism.

\section{The Strategies in Developing "Silk Road" Sport Tourism}

Expand Channels, Attract Social Capital and Invest More Money. First, we need to actively enlist the fund support of relevant government departments. The development of sports tourism is also the implementation of "One Belt One Road" and the "Bridgehead" strategy, so we should get attention of the relative government departments and the fund support. Secondly, the development of "Silk Road" sports tourism should follow the basic laws of market economy and take the market as the leading factor. The funds required to open resource market and the operational construction should rely on the market and the investment promotion. By using the principle of market economy, the state-owned, collective and individual business entities are supported and encouraged to participate in the management of "Silk Road" sports tourism. Meanwhile, we should attract some powerful domestic large and medium-sized enterprises to develop sports tourism projects in order to gradually break the small pattern of the "Silk Road" sports tourism in Yunnan.

Implement The Task: I Have Things While Others Don't. Mine Are Better While They Have. While planning the development of sports tourism, the plan should be unified, overall layout and emphasized. Focusing on the sports tourism of Tea Horse Trade Road which conforms to "I have things while others don't", developing the hiking tour of the Tea Horse Trade Road, the experience tour of Caravan culture and so on. Bringing the idea " Mine are better while they have " into reality. Combining all kinds of the ethnic customs and festival activities. Relying on various resources to develop sports tourism comprehensively. Highlighting the superiority and the resultant force. Strengthening brand consciousness. Highlighting the local characteristics and national features.

Protect The Cultural Connotation. We should take advantages of the rare culture resource to improve the cultural connotation of the "Silk Road" sports tourism. First of all, It is important to focus on the tour development of sports culture, such as the development of sports culture in the caves of Xishan scenic area, and the sports culture in Caravan of the Shuhe ancient town. Secondly, it is important to pay close attention to the development of traditional national sports tourism, and develop the viewing pattern of tourists to the participating pattern. 
Ensure The Sustainable Development. The relevant departments should quickly change their ideas and raise their awareness to support and manage the "Silk Road" sports tourism in general. First of all, the departments should investigate, evaluate and understand the value of the developed sports tourism resources and potential ones. Then they should find out the resources that can be developed preferentially and establish the corresponding management and supervision system. Secondly, they should maintain the relationship between the project development and the local ecological environment protection.

Cultivate Specialized Talents for Sports Tourism Actively. First of all, on the basis of excavating the existing human resources, we should foster senior specialized talents with knowledge of both sports and tourism, especially those with specific sports tourism knowledge, ability and quality. For example, we can set the major of tourism in sports colleges or we can carry out the courses about sports tourism or outdoor training in tourism colleges, so that the students can quickly adapt and competent to work they do in the future. Secondly, we should combine the sports tourism enterprises and the training institutions for sports tourism talents with the method of combining the production and learning.

\section{Acknowledgements}

Science Research Fund Project of Yunnan Provincial Education Department, NO: 2014C205Y.

\section{References}

[1] Guosheng Chen, Xiaoxia Yang. Developing Southwest Tourism Based On The Southwest Silk Road [J]. Economic Geography, 1997 (3).

[2] Xiaoling Qu. China's Southwest and Overseas Ancient Road: The Southern Silk Road And Its Research Report [J]. Northwest national Study, 2011 (1).

[3] Dongtao Zou. The Book of Great Development of Western China [M]. Beijing: People's Press, 12.2000. 